\title{
Intraperitoneal Mesh Implantation for Fascial Dehiscence and Open Abdomen
}

\author{
Moritz Scholtes • Anita Kurmann - Christian A. Seiler • \\ Daniel Candinas · Guido Beldi
}

Published online: 9 March 2012

(C) Société Internationale de Chirurgie 2012

\begin{abstract}
Background Postoperative fascial dehiscence and open abdomen are severe postoperative complications and are associated with surgical site infections, fistula, and hernia formation at long-term follow-up. This study was designed to investigate whether intraperitoneal implantation of a composite prosthetic mesh is feasible and safe.

Methods A total of 114 patients with postoperative fascial dehiscence and open abdomen who had undergone surgery between 2001 and 2009 were analyzed retrospectively. Contaminated (wound class 3) or dirty wounds (wound class 4) were present in all patients. A polypropylene-based composite mesh was implanted intraperitoneally in 51 patients, and in 63 patients the abdominal wall was closed without mesh implantation. The primary endpoint was incidence of incisional hernia, and the incidence of enterocutaneous fistula was a secondary endpoint.

Results The incidence of enterocutaneous fistulas after wound closure post-fascial dehiscence (13\% vs. $6 \%$ without and with mesh, respectively) or post-open abdomen ( $22 \%$ vs. $28 \%$ without and with mesh, respectively) was not significantly different. The incidence of incisional hernia was significantly lower with mesh implantation compared with no-mesh implantation in both contaminated $(4 \%$ vs. $28 \% ; p=0.025)$ and dirty abdominal cavities $(5 \%$ vs. $34 \% ; p=0.01)$.
\end{abstract}

Presented at the Annual Congress of the Swiss Surgical Societies, Interlaken, May 26-28, 2010.

M. Scholtes · A. Kurmann · C. A. Seiler · D. Candinas

G. Beldi $(\bowtie)$

Department of Visceral Surgery and Medicine, Bern University

Hospital, University of Bern, 3010 Bern, Switzerland

e-mail: guido.beldi@insel.ch
Conclusions Intra-abdominal contamination is not a contraindication for intra-abdominal mesh implantation. The incidence of enterocutaneous fistula is not elevated despite the presence of contamination. The rate of incisional hernias is significantly reduced after intraperitoneal mesh implantation for postoperative fascial dehiscence or open abdomen.

\section{Introduction}

Fascial dehiscence with bowel eventration and open abdomen are potential sequelae of abdominal surgery and are associated with significant morbidity and cost. The incidence of fascial dehiscence in patients with various degrees of wound contamination is as high as $3 \%$ and is associated with mortality as high as 44\% [1-5]. Reoperations for such wound-related complications are associated with an incidence of incisional hernia as high as 54\% [6]. Numerous strategies have been proposed to reduce wound dehiscence and incisional hernia, including delayed reconstruction using flaps, lateral incisions, or dynamic systems [7-10]. In a recent publication, a combination of vacuum- and meshmediated traction was shown to be safe and reduce the incidence of large planned ventral hernia [11]. However, long-term results are missing and a high incidence of incisional hernia is expected. In this study, we present our results with primary mesh implantation as a new option for these difficult situations. This strategy was introduced to prevent early and late complications, such as recurrent fascial dehiscence and incisional hernia. However, mesh implantation may be associated with complications, such as chronic infection and enterocutaneous fistula formation [12, 13]. This study was designed to determine if implantation of a polypropylene-based composite mesh is safe in such clinical scenarios that are associated with contaminated or dirty 
wounds and assess the long-term follow up of these patients, especially regarding hernia formation.

\section{Methods}

Patient characteristics

All patients with acute postoperative fascial dehiscence or open abdomen treated at our institution between January 2001 and December 2009 were recorded in a digital database and analyzed retrospectively. To assess and compare preoperative risk factors, the surgical risk scale (SRS) was calculated as described previously [14]. By definition of the Centers of Disease Control and Prevention, fascial dehiscence and open abdomen are contaminated (wound class 3; open wounds, acute nonpurulent infection) or dirty wounds (wound class 4; active infection present) [15]. Approval for the study was obtained from the local ethical committee.

\section{Surgical technique}

Patients were divided into four groups based on the surgical techniques used for abdominal closure, as shown in Fig. 1. When closure of the abdominal wall was technically possible, the abdominal fascia was sutured using PDS ${ }^{\circledR}$ loop 1 sutures (Ethicon Sarl, Neuchatel, Switzerland) or additional Vicryl ${ }^{\circledR}$ strings (Ethicon Sarl, Neuchatel, Switzerland) (group: fascial closure without mesh implantation). In the second group (fascial closure with mesh implantation), the mesh was placed intraperitoneally and fixed with single knot sutures (Prolene ${ }^{\circledR}$ 2-0, Ethicon Sarl, Neuchatel, Switzerland), endosurgical staples (Protack ${ }^{\circledR}$,

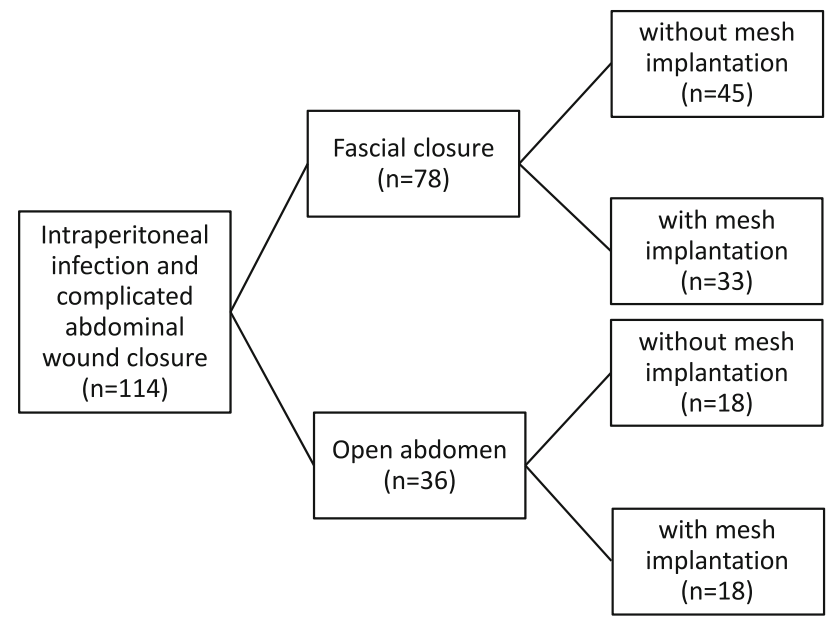

Fig. 1 Surgical techniques used in this study. A complicated abdominal closure was defined as closure after fascial dehiscence or open abdomen
Covidien AG, Wollerau, Switzerland), or a combination of both. The mesh consisted of nonabsorbable polypropylene composite material (Parietene ${ }^{\circledR}$, Parietex ${ }^{\circledR}$, Covidien AG, or Dynamesh ${ }^{\circledR}$, Laubscher \& Co AG, Hölstein, Switzerland). In all patients with open abdomen, a fascial closure was attempted intraoperatively but was technically not possible. Patients who underwent open abdomen without mesh implantation were treated with vacuum-assisted closure (VAC ${ }^{\circledR}$, KCI medical GmbH, Rümlang, Switzerland) alone. Abdominal VAC dressing was placed intraperitoneally, and VAC was performed using negative pressure between 25 and $125 \mathrm{mmHg}$ and was subsequently reduced in magnitude. In the last group (open abdomen with mesh implantation), the same type of mesh was sutured to the peritoneum followed by wound closure with VAC.

Follow-up

Clinical follow-up investigations were conducted on an outpatient basis by the responsible surgeon or the patient's general practitioner. When applicable, date and cause of death were recorded.

\section{Statistics}

All statistical tests were performed by using SPSS Statistics (Version 17.0.0, SPSS Inc., Chicago, IL). Categorical data were analyzed with the Fisher's exact test; continuous data were analyzed with Student's $t$ test. A cutoff value of $p<0.05$ was used to determine statistical significance.

\section{Results}

Patient characteristics and risk factors were similar between the groups (Table 1). Indications for the initial operations included elective, emergent, or urgent operations for tumors, hollow organ perforation, acute or chronic inflammation of visceral organs, incarcerated hernia, and mechanical ileus (Table 2).

Early postoperative complications were compared between no mesh and mesh implantation in patients with wound class 3 (Table 3) and wound class 4 (Table 4). The incidence of incisional hernia was significantly lower with mesh implantation than without it, irrespective of wound class. The incidence of enterocutaneous fistulas did not differ between the mesh and nonmesh groups. Hospital stay was significantly longer in patients with wound class 4 compared with those with wound class $3(50 \pm 39$ days vs. $32 \pm 19$ days, respectively; $p=0.002$ ).

Subgroup analysis was performed of patients with fascial closure (Table 5) and for patients with open abdomen (Tables 6). The incidence of incisional hernia was significantly 
Table 1 Characteristics of all patients who underwent fascial closure or open abdomen with or without mesh implantation

\begin{tabular}{lccl}
\hline & $\begin{array}{c}\text { No mesh } \\
(n=63)\end{array}$ & $\begin{array}{l}\text { Mesh } \\
(n=51)\end{array}$ & $P$ value $^{\mathrm{a}}$ \\
\hline Male & $37(58.7)$ & $32(62.7)$ & 0.703 \\
Age (year)* & $61.3(22-85)$ & $64.3(22-86)$ & $0.059^{\mathrm{b}}$ \\
BMI $>30 \mathrm{~kg} / \mathrm{m}^{2}$ & $18(28.6)$ & $8(15.7)$ & 0.12 \\
Malignancy within past & $20(31.7)$ & $27(52.9)$ & 0.035 \\
$\quad 5$ years & $7(11.1)$ & $7(13.7)$ & 0.777 \\
Diabetes mellitus & $16(25.4)$ & $15(29.4)$ & 0.676 \\
Cardiovascular disease & $12(19.0)$ & $15(29.4)$ & 0.268 \\
COPD & $9(14.3)$ & $10(19.6)$ & 0.462 \\
Immunosuppression & $45(81.8)$ & $38(86.4)$ & 0.833 \\
ASA score 3 or 4 & $27(49.1)$ & $28(63.6)$ & 0.258 \\
SRS $\geq 10$ &
\end{tabular}

Data in parentheses are percentages unless otherwise indicated; * data are median (range)

$B M I$ body mass index; $C O P D$ chronic obstructive pulmonary disease; ASA American Society of Anesthesiologists score; SRS surgical risk scale

${ }^{\mathrm{a}}$ Fisher exact test; ${ }^{\mathrm{b}}$ Students $t$ test

Table 2 Indications for the primary operation

\begin{tabular}{lccl}
\hline & $\begin{array}{c}\text { No mesh } \\
(n=63)\end{array}$ & $\begin{array}{l}\text { Mesh } \\
(n=51)\end{array}$ & $P$ value* \\
\hline Malignant tumor & $15(23.8)$ & $18(35.3)$ & 0.215 \\
Hollow organ perforation & $22(34.9)$ & $14(27.5)$ & 0.424 \\
Acute or chronic inflammation & $11(17.5)$ & $4(7.8)$ & 0.168 \\
$\begin{array}{l}\text { Incarcerated hernia and } \\
\text { mechanical ileus }\end{array}$ & $1(1.6)$ & $3(5.9)$ & 0.323 \\
Hemorrhage & $1(1.6)$ & $2(3.9)$ & 0.586 \\
Elective hernia repair & $1(1.6)$ & $2(3.9)$ & 0.586 \\
Intestinal ischemia & $0(0.0)$ & $2(3.9)$ & 0.198 \\
Transplantation & $2(3.2)$ & $1(2)$ & 0.414 \\
Vascular surgery & $2(3.2)$ & $1(2)$ & 0.414 \\
Trauma & $1(1.6)$ & $0(0)$ & 1 \\
Others & $7(11.1)$ & $4(7.8)$ & 0.752 \\
\hline
\end{tabular}

Data in parentheses are percentages

* Fisher's exact test

lower with mesh implantation than without it in both the subgroup of fascial closure (3\% vs. $22 \% ; p=0.02$ ) and the subgroup of patients with open abdomen (6\% vs. $100 \%$; $p<0.001)$.

\section{Discussion}

The results of this study reveal the safety of intraperitoneal mesh implantation despite the presence of contamination.
In particular, the study shows a significantly reduced incidence of abdominal wall hernia without an increased risk of enterocutaneous fistula formation for critical abdominal wounds that are characterized by intraperitoneal infection and complicated abdominal wound closure.

In this series, only patients with postoperative fascial dehiscence or open abdomen were included. A total of $22 \%$ of patients developed incisional hernias after fascial closure without mesh implantation, and $90 \%$ of these patients underwent operative hernia repair during follow-up. Such incidence of incisional hernia is consistent with previous findings, although higher rates have been observed [4, 6, 16]. In the present series, mesh implantation with fascial closure reduced the incidence of incisional hernia significantly without additional morbidity.

Open abdomen may be necessary under specific conditions in patients with generalized peritonitis or for posttraumatic damage control [5, 17, 18]. The resulting abdominal wall defect after open abdomen can be quite large, and subsequent reconstruction may be associated with high additional morbidity [19]. Except for one patient, no reconstructive surgery was necessary after mesh implantation for open abdomen. This patient developed a paraprosthetical hernia after open abdomen with mesh implantation due to an undersized mesh, which had to be replaced with a larger mesh 1 week after surgery for open abdomen. All patients with open abdomen without mesh implantation had, by definition, an incisional hernia, and $50 \%$ of these patients underwent operative repair of their hernia.

Enterocutaneous fistula formation is a potentially serious complication in patients with postoperative fascial dehiscence or open abdomen [18]. In the present study, the incidence of enterocutaneous fistulas was higher after open abdomen than after direct fascial closure. However, the main finding of this study is that the incidence of enterocutaneous fistulas is not associated with the presence of intraabdominal mesh. One group has shown an association of intraperitoneal mesh implantation with the formation of enterocutaneous fistula [20]. However, in that study no composite meshes were used.

In patients undergoing fascial closure, the observed incidence of fistula formation $(13.3 \%$ without mesh vs. $8.8 \%$ with mesh) is comparable to that observed in previous studies [21, 22]. The incidence of fistulas after open abdomen ( $22 \%$ without mesh vs. $28 \%$ with mesh) also is comparable to that in previous studies [23-26].

All of our meshes in patients with open abdomen were in contact with the environment and healing by secondary intention was possible. Mesh infection as reported in other series potentially prolonged healing [27]. However, in the current series, we did not observe an increased incidence of infectious complications associated with mesh implantation. No mesh-explantation due to infection was required. 
Table 3 Perioperative and postoperative results of patients with wound class 3 (contaminated abdomen)

\begin{tabular}{|c|c|c|c|}
\hline & $\begin{array}{l}\text { No mesh } \\
(n=29)\end{array}$ & $\begin{array}{l}\text { Mesh } \\
(n=28)\end{array}$ & $P$ value \\
\hline \multicolumn{4}{|l|}{ Perioperative results } \\
\hline $\begin{array}{l}\text { Time between primary } \\
\text { operation and abdominal } \\
\text { wall closure (days)* }\end{array}$ & $10(1-229)$ & $12(4-82)$ & $0.594^{\mathrm{c}}$ \\
\hline VAC-therapy, $n$ & $16(55.2)$ & $21(75)$ & 0.167 \\
\hline $\begin{array}{l}\text { Negative pressure of VAC } \\
(\mathrm{mmHg})^{*}\end{array}$ & $88(40-125)$ & $75(50-125)$ & 0.831 \\
\hline Hospital stay (days) ${ }^{\mathrm{a}}$ & $28( \pm 17.9)$ & $36( \pm 20.8)$ & $0.146^{\mathrm{c}}$ \\
\hline ICU stay (days) ${ }^{\mathrm{a}}$ & $6( \pm 11.3)$ & $3( \pm 6.9)$ & $0.18^{\mathrm{c}}$ \\
\hline \multicolumn{4}{|l|}{ Early Complications } \\
\hline Enterocutaneous fistula, $n$ & $5(17.2)$ & $3(10.7)$ & 0.706 \\
\hline 30 day mortality & $5(17.2)$ & $1(3.6)$ & 0.194 \\
\hline \multicolumn{4}{|l|}{ Follow-up } \\
\hline Months of follow-up ${ }^{a}$ & $17( \pm 24)$ & $8( \pm 11.7)$ & $0.079^{\mathrm{c}}$ \\
\hline Overall mortality & $10(34.5)$ & $9(32.1)$ & 1 \\
\hline $\begin{array}{l}\text { Incidence of incisional } \\
\text { hernia, } n\end{array}$ & 8 (27.6) & $1(3.6)$ & 0.025 \\
\hline $\begin{array}{l}\text { Operation for incisional } \\
\text { hernia, } n\end{array}$ & $7(24.1)$ & $1(3.6)$ & 0.052 \\
\hline
\end{tabular}

$V A C$ vacuum-assisted closure; $I C U$ intensive care unit

* Data are median (range)

${ }^{\text {a }}$ Data are mean (standard deviation)

${ }^{\mathrm{b}}$ Fisher exact test

c Student's $t$ test

A limitation of this study was its retrospective design, and we cannot exclude selection bias determined by the indication for mesh implantation, such as existing contamination or fascial retraction. However, the conditions investigated are rare events, limiting the feasibility of a prospective randomized trial. The groups were comparable in terms of patient characteristics, risk factors, and comorbidities. Furthermore, comorbidities, general health status, type, and invasiveness of the procedure were similar as assessed by the surgical risk scale [14]. These similarities between groups helped to reduce the possibility that confounding factors caused the observed differences associated with mesh versus nonmesh procedures. The estimated mortality associated with a surgical risk scale of 10 is approximately $19 \%$ and increases to $90 \%$ with the maximum score of 14 [28]. Most patients in this study had a surgical risk scale of 10 and higher and our overall mortality rate was $15.7 \%$.

In conclusion, the implantation of nonabsorbable meshes for postoperative fascial dehiscence or open abdomen, despite a contaminated or dirty abdomen, is associated with a reduced incidence of incisional abdominal wall hernias and should be considered as a therapeutic option in these critically ill patients. Overall mortality rates
Table 4 Perioperative and postoperative results of patients with wound class 4 (dirty abdomen)

\begin{tabular}{|c|c|c|c|}
\hline & $\begin{array}{l}\text { No mesh } \\
(n=35)\end{array}$ & $\begin{array}{l}\text { Mesh } \\
(n=22)\end{array}$ & $P$ value $^{\mathrm{b}}$ \\
\hline \multicolumn{4}{|l|}{ Perioperative results } \\
\hline $\begin{array}{l}\text { Time between primary } \\
\text { operation and abdominal } \\
\text { wall closure (days)* }\end{array}$ & $11(2-65)$ & $11(4-28)$ & $0.175^{\mathrm{c}}$ \\
\hline VAC-therapy, $n$ & $30(85.7)$ & $19(86.4)$ & 1 \\
\hline $\begin{array}{l}\text { Negative pressure of VAC } \\
(\mathrm{mmHg})^{*}\end{array}$ & $75(25-125)$ & $75(50-125)$ & 0.496 \\
\hline Hospital stay (days) $^{\mathrm{a}}$ & $53( \pm 44.3)$ & $47( \pm 30.3)$ & $0.544^{\mathrm{c}}$ \\
\hline ICU stay (days) ${ }^{\mathrm{a}}$ & $10( \pm 15.5)$ & $5( \pm 9.4)$ & $0.108^{\mathrm{c}}$ \\
\hline \multicolumn{4}{|l|}{ Early complications } \\
\hline Enterocutaneous fistula, $n$ & $6(17.1)$ & $3(13.6)$ & 1 \\
\hline 30 day mortality & $8(22.9)$ & $4(18.2)$ & 0.75 \\
\hline \multicolumn{4}{|l|}{ Follow-up } \\
\hline Months of follow-up ${ }^{a}$ & $10( \pm 15.7)$ & $7( \pm 7.7)$ & $0.372^{\mathrm{c}}$ \\
\hline Overall mortality & $12(34.3)$ & $5(22.7)$ & 0.391 \\
\hline $\begin{array}{l}\text { Incidence of incisional } \\
\text { hernia, } n\end{array}$ & $12(34.3)$ & $1(4.5)$ & 0.01 \\
\hline $\begin{array}{l}\text { Operation for incisional } \\
\text { hernia, } n\end{array}$ & $11(31.4)$ & $0(0)$ & 0.004 \\
\hline
\end{tabular}

$V A C$ vacuum-assisted closure; $I C U$ intensive care unit

Data in parentheses are percentages unless otherwise indicated

* data are median (range)

${ }^{\text {a }}$ data are mean (standard deviation)

${ }^{\mathrm{b}}$ Fisher exact test

c Student's $t$ test

Table 5 Subgroup analysis of patients with fascial closure

\begin{tabular}{lccc}
\hline & $\begin{array}{l}\text { No mesh } \\
(n=45)\end{array}$ & $\begin{array}{l}\text { Mesh } \\
(n=33)\end{array}$ & $P$ value $^{\mathrm{a}}$ \\
\hline $\begin{array}{l}\text { Wound class 3 } \\
\text { (contaminated), } n\end{array}$ & $23(51.1)$ & $22(66.7)$ & 0.246 \\
$\begin{array}{l}\text { Wound class 4 (dirty), } n \\
\text { Early complications }\end{array}$ & $22(48.9)$ & $11(33.3)$ & 0.246 \\
$\begin{array}{l}\text { Enterocutaneous fistula } \\
\begin{array}{l}\text { Length of hospital stay } \\
\text { (days)* }\end{array}\end{array}$ & $6(13.3)$ & $2(6.1)$ & 0.456 \\
$\begin{array}{l}\text { 30-days mortality } \\
\begin{array}{l}\text { Follow-up } \\
\text { Months of follow-up* }\end{array}\end{array}$ & $74( \pm 21.3)$ & $85.7( \pm 22.3)$ & $0.859^{\mathrm{b}}$ \\
$\begin{array}{l}\text { Overall mortality } \\
\text { Incidence of incisional } \\
\text { hernia, } n\end{array}$ & $10(22.2)$ & $7(21.2)$ & 1 \\
$\begin{array}{l}\text { Operation for incisional } \\
\text { hernia, } n\end{array}$ & $9(22.2)$ & $1(3)$ & 0.02 \\
\hline
\end{tabular}

* Data in parentheses are percentages unless otherwise indicated

Data are mean (standard deviation)

a Fisher's exact test

b Student's $t$ test 
Table 6 Subgroup analysis of patients with open abdomen

\begin{tabular}{lccc}
\hline & $\begin{array}{l}\text { No mesh } \\
(n=18)\end{array}$ & $\begin{array}{l}\text { Mesh } \\
(n=18)\end{array}$ & $P$ value $^{\mathrm{a}}$ \\
\hline $\begin{array}{l}\text { Wound class } 3 \\
\text { (contaminated), } n\end{array}$ & $6(33.3)$ & $6(33.3)$ & 1 \\
$\begin{array}{l}\text { Wound class 4 (dirty), } n \\
\begin{array}{l}\text { Early complications } \\
\text { Enterocutaneous fistula }\end{array}\end{array}$ & $12(66.7)$ & $12(66.7)$ & 1 \\
$\begin{array}{l}\text { Length of hospital stay } \\
\text { (days)* }\end{array}$ & $50( \pm 43.3)$ & $54( \pm 31.9)$ & $0.784^{\mathrm{b}}$ \\
$\begin{array}{l}30 \text { days mortality } \\
\begin{array}{l}\text { Follow-up } \\
\text { Months of follow-up* }\end{array}\end{array}$ & $6(33.3)$ & $4(22.2)$ & 0.711 \\
$\begin{array}{l}\text { Overall mortality } \\
\begin{array}{l}\text { Incidence of incisional } \\
\text { hernia, } n\end{array}\end{array}$ & $11.0(61.1)$ & $8.0(44.4)$ & 0.505 \\
$\begin{array}{l}\text { Operation for incisional } \\
\text { hernia, } n\end{array}$ & $9(50)$ & $1(5.6)$ & 0.007 \\
\hline
\end{tabular}

Data in parentheses are percentages unless otherwise indicated

* Data are mean (standard deviation)

${ }^{a}$ Fisher exact test

b Student's $t$ test

and enterocutaneous fistula formation rates were not influenced by the use of mesh.

Conflicts of interest None.

Funding None.

\section{References}

1. Bucknall TE, Cox PJ, Ellis H (1982) Burst abdomen and incisional hernia: a prospective study of 1129 major laparotomies. $\mathrm{Br}$ Med J (Clin Res Ed) 284:931-933

2. Seiler CM, Bruckner T, Diener MK et al (2009) Interrupted or continuous slowly absorbable sutures for closure of primary elective midline abdominal incisions: a multicenter randomized trial (INSECT: ISRCTN24023541). Ann Surg 249:576-582

3. van Ramshorst GH, Eker HH, Harlaar JJ et al (2010) Therapeutic alternatives for burst abdomen. Surg Technol Int 19:111-119

4. Madsen G, Fischer L, Wara P (1992) Burst abdomen-clinical features and factors influencing mortality. Dan Med Bull 39: $183-185$

5. Tremblay LN, Feliciano DV, Schmidt J et al (2001) Skin only or silo closure in the critically ill patient with an open abdomen. Am J Surg 182:670-675

6. Moussavian MR, Schuld J, Dauer D et al (2010) Long-term follow-up for incisional hernia after severe secondary peritonitisincidence and risk factors. Am J Surg 200:229-234

7. Verdam FJ, Dolmans DE, Loos MJ et al (2011) Delayed primary closure of the septic open abdomen with a dynamic closure system. World J Surg 35:2348-2355

8. Esmat ME (2006) A new technique in closure of burst abdomen: TI, TIE and TIES incisions. World J Surg 30:1063-1073
9. Leppaniemi A, Tukiainen E (2012) Planned hernia repair and late abdominal wall reconstruction. World J Surg 36:511-515

10. Marwah S, Marwah N, Singh M et al (2005) Addition of rectus sheath relaxation incisions to emergency midline laparotomy for peritonitis to prevent fascial dehiscence. World J Surg 29:235-239

11. Acosta S, Bjarnason T, Petersson U et al (2011) Multicentre prospective study of fascial closure rate after open abdomen with vacuum and mesh-mediated fascial traction. $\mathrm{Br} \mathrm{J}$ Surg 98:735-743

12. Balique JG, Benchetrit S, Bouillot JL et al (2005) Intraperitoneal treatment of incisional and umbilical hernias using an innovative composite mesh: four-year results of a prospective multicenter clinical trial. Hernia 9:68-74

13. Bee TK, Croce MA, Magnotti LJ et al (2008) Temporary abdominal closure techniques: a prospective randomized trial comparing polyglactin 910 mesh and vacuum-assisted closure. J Trauma 65:337-342 discussion 342-334

14. Sutton R, Bann S, Brooks M et al (2002) The Surgical Risk Scale as an improved tool for risk-adjusted analysis in comparative surgical audit. Br J Surg 89:763-768

15. Mangram AJ, Horan TC, Pearson ML et al (1999) Guideline for prevention of surgical site infection, 1999. Centers for disease control and prevention (CDC) Hospital infection control practices advisory committee. Am J Infect Control 27:97-132 quiz 133-134; discussion 196

16. Mingoli A, Puggioni A, Sgarzini G et al (1999) Incidence of incisional hernia following emergency abdominal surgery. Ital J Gastroenterol Hepatol 31:449-453

17. Mughal MM, Bancewicz J, Irving MH (1986) 'Laparostomy': a technique for the management of intractable intra-abdominal sepsis. Br J Surg 73:253-259

18. Teixeira PG, Salim A, Inaba K et al (2008) A prospective look at the current state of open abdomens. Am Surg 74:891-897

19. DiCocco JM, Magnotti LJ, Emmett KP et al (2010) Long-term follow-up of abdominal wall reconstruction after planned ventral hernia: a 15-year experience. J Am Coll Surg 210:686-695-695688

20. Connolly PT, Teubner A, Lees NP et al (2008) Outcome of reconstructive surgery for intestinal fistula in the open abdomen. Ann Surg 247:440-444

21. Burger JW, Luijendijk RW, Hop WC et al (2004) Long-term follow-up of a randomized controlled trial of suture versus mesh repair of incisional hernia. Ann Surg 240:578-583 discussion 583-575

22. Leber GE, Garb JL, Alexander AI et al (1998) Long-term complications associated with prosthetic repair of incisional hernias. Arch Surg 133:378-382

23. Bosscha K, Hulstaert PF, Visser MR et al (2000) Open management of the abdomen and planned reoperations in severe bacterial peritonitis. Eur J Surg 166:44-49

24. Tsuei BJ, Skinner JC, Bernard AC et al (2004) The open peritoneal cavity: etiology correlates with the likelihood of fascial closure. Am Surg 70:652-656

25. Anderson O, Putnis A, Bhardwaj R et al (2010) Short and long term outcome of laparostomy following intra-abdominal sepsis. Colorectal Dis 13(2):e20-e32

26. Subramonia S, Pankhurst S, Rowlands BJ et al (2009) Vacuumassisted closure of postoperative abdominal wounds: a prospective study. World J Surg 33:931-937

27. Cobb WS, Carbonell AM, Kalbaugh CL et al (2009) Infection risk of open placement of intraperitoneal composite mesh. Am Surg 75:762-767 discussion 767-768

28. Brooks MJ, Sutton R, Sarin S (2005) Comparison of Surgical Risk Score, POSSUM and p-POSSUM in higher-risk surgical patients. Br J Surg 92:1288-1292 